\title{
Size Effects on Fracture Parameters of High Alumina Refractories
}

\author{
Wenjie Yuan ${ }^{a, b *}$, Hai Tang ${ }^{a}$, Qingyou Zhu ${ }^{a}$, Danyang Zhang ${ }^{a}$ \\ ${ }^{a}$ The State Key Laboratory of Refractories and Metallurgy, Wuhan University of Science and \\ Technology, Wuhan 430081, China \\ ${ }^{b}$ National-provincial Joint Engineering Research Center of High Temperature Materials and Lining \\ Technology, Wuhan University of Science and Technology, Wuhan 430081, China
}

Received: February 06, 2018; Revised: April 27, 2018; Accepted: June 08, 2018

\begin{abstract}
The randomness of phase compositions and their distribution as well as the micro cracks and pores in refractories result in the dependence of mechanical properties on the sample size. In this work, the size effects on fracture parameters including bending strength, elastic modulus and fracture toughness of high alumina bricks were investigated by testing samples of different sizes according to the national standard in China. The results showed that the smaller samples presented higher strength, while the larger samples possessed greater elastic modulus. Weibull modulus $m$ of bending strength for high alumina bricks calculated for samples of two sizes, each group featured 32 samples, ranged from 11 to 12 , which was higher than in other refractories such as low grade high alumina, magnesia-carbon and magnesia-chrome bricks. The scatter of the average strength and its standard deviation became stable when the sample number was more than 20. The fractal dimension of fracture surface for high alumina bricks was inversely and directly proportional to the sample size and the fracture toughness, respectively. The estimated fracture toughness of high alumina bricks was close to window glass and less than alumina and mullite.
\end{abstract}

Keywords: Size effect, strength, elastic modulus, high alumina bricks.

\section{Introduction}

The size effect on structural strength is a scaling problem of failure". In general, the trend of "smaller is stronger" for the size effect in various materials such as metal, ceramic and concrete was presented ${ }^{2-5}$. The size effect of materials was investigated from different viewpoints including statistics, strain gradients, boundary layers and fracture energy ${ }^{6}$. However, the strength of a structure could not be predicted according to the correlation of the strength and the sample size only using a simple scaling law ${ }^{7}$.

Refractories are multi-scale multiphase inhomogeneous materials. They are made with raw materials of different particle sizes and shapes and used as the lining and insulation in the high temperature units in many industries. The fracture behavior of refractories is complex due to the random distribution of different components of microstructure, the micro cracks and pores. The strength of refractories is normally an essential parameter to evaluate their quality ${ }^{8}$. The value of the strength provides an important reference for the design of the linings and equipments for the high-temperature service. Elastic modulus values are important to determine thermal shock resistance of materials ${ }^{9}$. Alternatively the fracture toughness and the fracture dimension of fracture surfaces can be stated to characterize the fracture behavior of refractories ${ }^{10-12}$. Nowadays, the refractories industry was impacted by cutting overcapacity of iron and steel making and the rising price of raw materials. The accurate evaluation and effective use of refractories are particularly significant for achieving the long service life.

The researchers and engineers had paid significant attention to the above-mentioned topic. Studies showed that the strength for the three-point bending specimen of $\mathrm{MgO}-\mathrm{C}$ bricks was larger than that for diametral compression of $\mathrm{MgO}-\mathrm{C}$ nozzle because the effective volume of the former was smaller ${ }^{13}$. It was demonstrated that the three-point bending test was a simple and highly reliable test suitable for monolithic refractories ${ }^{14}$. Considering the national standard in China (GB/T 3001-2007), there were two options for the geometric size of refractories when the cold modulus of rupture was measured. Nevertheless, the recommended ratio of span to depth was less than 4 for the measurement of the fracture toughness of refractories by a three-point bending test $\mathrm{t}^{15}$. Therefore, which size is more appropriate need to be determined, taking into account both the representativeness and accuracy of the measurement. Furthermore, what is the size effect on the elastic modulus of refractories needs to be discussed because the maximum allowable temperature difference in refractories was closely correlated to the elastic modulus ${ }^{16}$.

On the other hand, the distribution of the measured strength values of materials was usually well described by the Weibull statistics ${ }^{17}$. In two-parameter Weibull function, failure probability $P$ can be described by 


$$
P=1-\exp \left(-\left(\frac{\sigma}{\sigma_{0}}\right)^{m}\right)
$$

where $m$ is the Weibull modulus and $\sigma_{0}$ is the scale parameter ${ }^{18}$.

For the linear least-squares method, Eq. 1 can be expressed as a linear function:

$$
\ln \ln (1 /(1-P))=m \ln \sigma-m \ln \sigma_{0}
$$

Thus it can be seen that the accurate evaluation of the variation of the strength and the reliability of materials depended on the size effect of materials because the variability of the strength was reflected in Weibull modulus ${ }^{19}$, which was used in the reliability assessment ${ }^{20}$.

Based on the above problem, high alumina bricks as a kind of typical refractory were selected as the research object in this work. Size effects on strength and elastic modulus of high alumina bricks were investigated. The Weibull modulus and the reliability of high alumina bricks were estimated for samples of two sizes. The fracture toughness of samples calculated based on the elastic modulus and the fractal dimension of the fracture surface was also discussed.

\section{Experimental Procedure}

The high alumina brick produced by a domestic company was selected. The chemical composition of bricks measured by inductively coupled plasma atomic emission spectroscopy (ICP-AES, IRIS Advantage ER/S, Thermo Elemental, USA) is listed in Table 1.

High-alumina bricks were cut into 32 samples for each size of $25 \mathrm{~mm} \times 25 \mathrm{~mm} \times 150 \mathrm{~mm}$ and $40 \mathrm{~mm} \times 40 \mathrm{~mm} \times 200$ $\mathrm{mm}$ by using a special cutting machine. Cold modulus of rupture for bricks was measured by a three-point bending test instrument (E43.504, MTS, China) with the span of 125 and $180 \mathrm{~mm}$ respectively according to GB/T 3001-2007. The images of fracture surfaces for every sample were recorded by a digital camera. The slit island method was applied to calculate the fractal dimension of fracture surfaces. The details about the estimation were shown in Ref. ${ }^{21}$. Elastic modulus of bar samples was tested by (RFDA, HTVP1600, IMCE, Belgium) in accordance with ASTM E1876-2007. The measurement principle is based on tapping the sample with a small projectile and recording the induced vibration signal with a microphone. The resonant frequency is determined by the collected vibration signal. The elastic modulus is calculated by the software based on the classical beam theory.

\section{Results and Discussion}

The load-displacement curves of high alumina bricks from the three-point bending tests are shown in Fig. 1. The large scale samples had higher maximum loads than the smaller ones due to the areas of cross-section. The maximum displacements varied from 0.41 to $0.81 \mathrm{~mm}$ for the small samples and from 0.46 to $0.9 \mathrm{~mm}$ for the larger samples. Cold modulus of rupture for high alumina bricks are listed in ascending order as shown in Fig. 2. The strength of the small and large samples covered the range with 18.6 to 28.4 $\mathrm{MPa}$ and 18.8 to $26.9 \mathrm{MPa}$, respectively. The former was basically greater than the later. The mean strengths and its standard deviations were $23.7 \pm 2.70$ and $22.3 \pm 2.12$ $\mathrm{MPa}$, which was consistent with the variation of the mean strength of sintered silicon nitride and alumina as well as the decrease of standard deviation with the specimen size 22-24. The probability of existence a critical flaw in a large sample was higher than the small one ${ }^{25}$, so the smaller samples presented higher strength.

Figure 3 shows the two-parameter Weibull fits for samples plotted according to Eq. 2. From Table 2, Weibull modulus $m$ as a characteristic of the spread of the bending strength for high alumina bricks calculated by using probability estimator $P_{i}=(i-0.5) / \mathrm{N}$ in this work was higher than other refractories such as low grade high alumina, magnesia-carbon and magnesia-chrome bricks ${ }^{26-28}$. This could be accounted for by the different compositions, bonds and porosities. It was demonstrated that stronger refractories presented lower spread of the strength than weaker ones such as 2 nd class high alumina bricks ${ }^{26}$. In general, the obtained Weibull modulus $m$ calculated with 32 samples with each size was in the range of traditional ceramics $(m=5 \text { to } 20)^{29}$. The scale parameter $\sigma_{0}$ (characteristic strength) standing for the stress at the failure probability of $63.2 \%$ was in the same sequence for the mean strength for the samples with two sizes. The high $m$-value of the larger sample indicated smaller spread of data for the sample of larger size. However, Weibull distribution fits better the smaller sample data from the goodness of fit $\left(\mathrm{r}^{2}\right)$. This could be attributed to the different statistical distribution of cracks in samples with distinct dimensions, which has the significantly influence on the fracture strength distribution ${ }^{30}$.

The function curves of the failure probability density (PDF) $f(\sigma)$ and reliability $R(\sigma)$ as defined in the reliability engineering ${ }^{31}$ are plotted in Fig. 4 . It can be seen that the PDF curve was stretched in the horizontal direction with increasing scale parameter value, which also resulted in a reduction in

Table 1. Chemical composition of high alumina bricks (wt\%)

\begin{tabular}{lcccccccc}
\hline $\mathrm{SiO}_{2}$ & $\mathrm{Al}_{2} \mathrm{O}_{3}$ & $\mathrm{Fe}_{2} \mathrm{O}_{3}$ & $\mathrm{CaO}$ & $\mathrm{MgO}$ & $\mathrm{K}_{2} \mathrm{O}$ & $\mathrm{Na}_{2} \mathrm{O}$ & $\mathrm{TiO}_{2}$ & $\mathrm{Cr}_{2} \mathrm{O}_{3}$ \\
\hline 11.32 & 77.73 & 2.27 & 1.24 & 0.45 & 0.72 & 0.02 & 3.51 & 0.18 \\
\hline
\end{tabular}



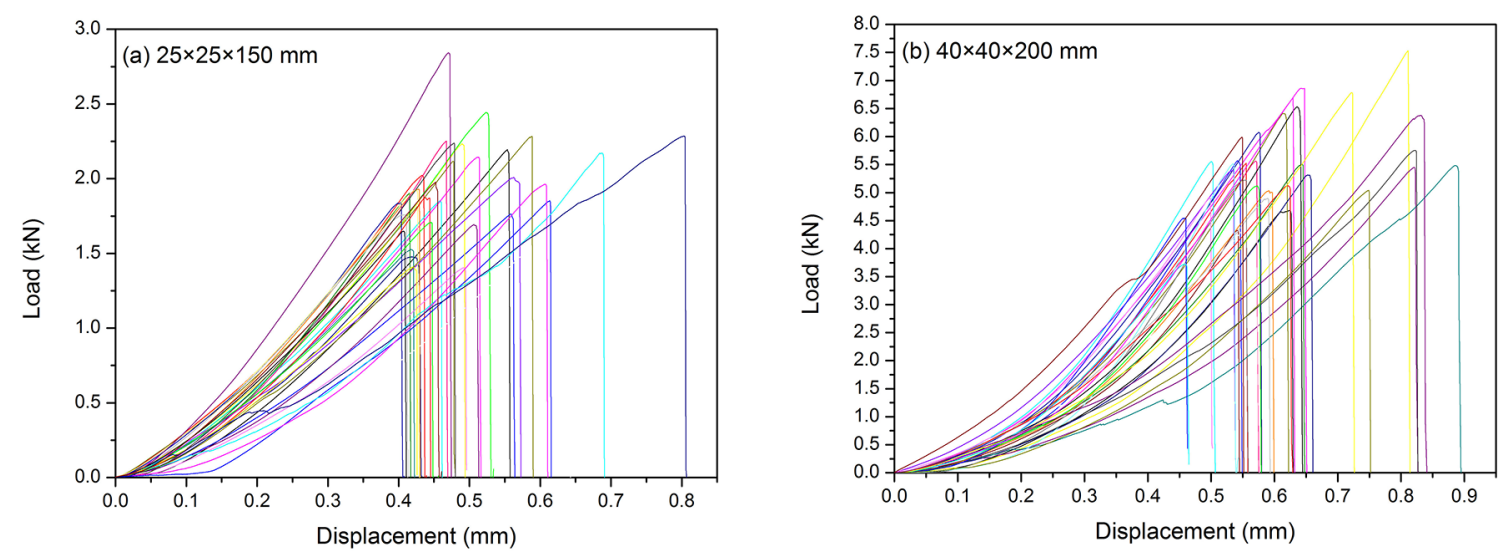

Figure 1. Load-displacement curves of high alumina bricks: (a) $25 \mathrm{~mm} \times 25 \mathrm{~mm} \times 150 \mathrm{~mm}$ and (b) $40 \mathrm{~mm} \times 40 \mathrm{~mm} \times 200 \mathrm{~mm}$

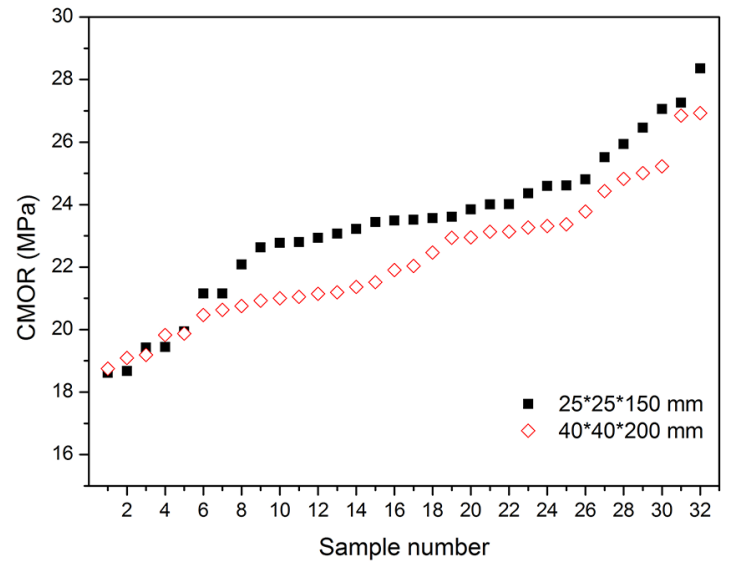

Figure 2. Distribution of cold modulus of rupture for high alumina bricks

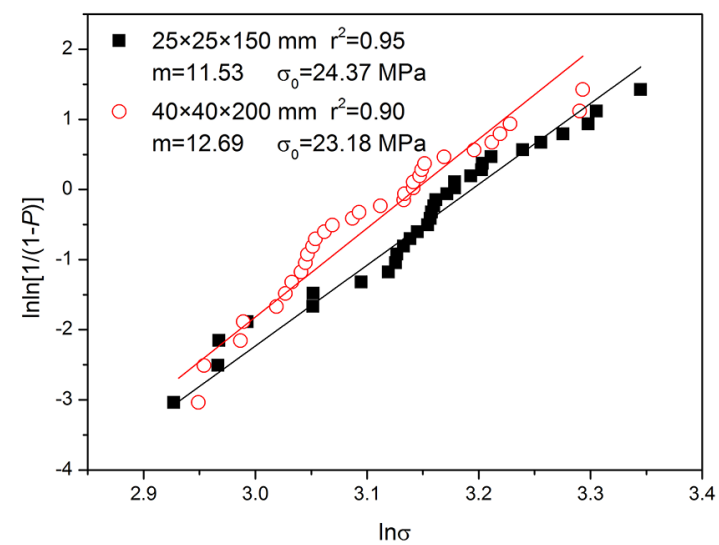

Figure 3. Weibull distribution curve of failure probability of high alumina bricks the peak value of the PDF in Fig. 4(a). It was demonstrated that the failure of the larger samples concentrated on lower strength. The reliability value at the certain strength can be estimated by the intersection of the curve and a vertical line from X-axis. So the smaller samples presented the higher reliability from Fig. 4(b).

The scatter of the measured strength for brittle materials could be well described by the Weibull statistics ${ }^{26}$. The sample number was one of key factors for the evaluation of the strength of brittle materials. From practical point of view, the question is how many samples are needed to assess accurately the average strength. Therefore, a series of sample group with different sample number including 3, 5, 10, 20 and 30 was assumed. In each sample group, the bending strength values were randomly selected from the measured values of 32 samples. Then the calculated mean strength and its standard deviation for two-sized samples of high alumina bricks were given in Fig. 5. It was very clear that the scatter of the mean strength and standard deviation were gradually declined with the increasing of the sample number. Both of above two values for the larger samples were less than those for the smaller samples. When the sample number was changed from 3 to 5 , the reduction of the variation of the mean strength was relatively greater. It can be seen that the fluctuation of the mean strength and standard deviation tended to stability by comparing the values of 20 and 30. Finally, the certain values were achieved when the sample number reached 32 . The results indicated that the sample number of high alumina bricks should be at least 20 in order to accurately determine the average strength with

Table 2. Comparison of Weibull modulus and scale parameter of bricks

\begin{tabular}{lccccc}
\hline & $\begin{array}{c}\text { High alumina } \\
(\text { small })\end{array}$ & $\begin{array}{c}\text { High alumina } \\
(\text { large })\end{array}$ & $\begin{array}{c}\text { High alumina } \\
\left(2^{\text {nd }} \text { class }\right)\left[{ }^{26}\right]\end{array}$ & $\mathrm{MgO}-\mathrm{C}\left[{ }^{27}\right]$ & ${\mathrm{MgO}-\mathrm{Cr}_{2} \mathrm{O}_{3}\left[{ }^{28}\right]}$ \\
\hline $\begin{array}{l}\text { Weibull modulus } \\
\begin{array}{l}\text { Scale parameter } \sigma_{0} \\
(\mathrm{MPa})\end{array}\end{array}$ & 11.53 & 12.69 & $3.79-5.98$ & $6.73-10.95$ & $8.01-10.65$ \\
\hline
\end{tabular}



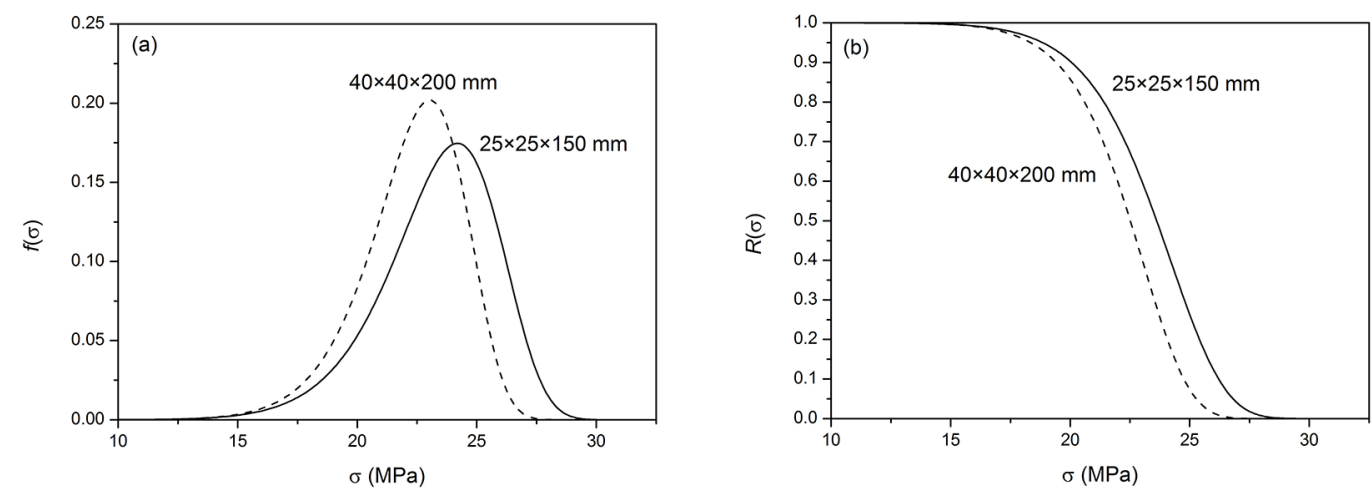

Figure 4. Relationship of strength and (a) probability density function and (b) reliability for high alumina bricks
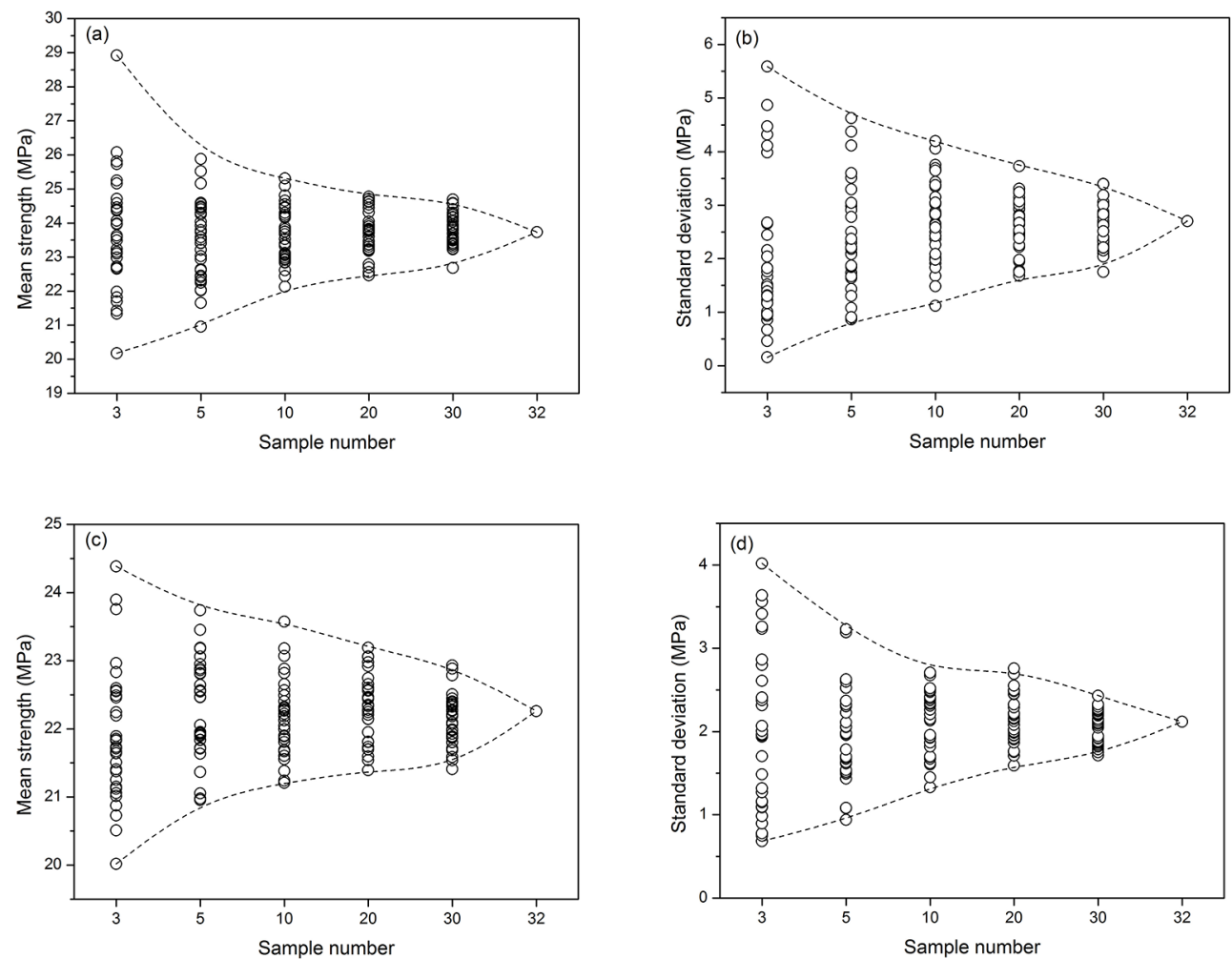

Figure 5. Mean value and standard deviation of the random selected test values of the bending strength for high alumina bricks: (a), (b) $25 \mathrm{~mm} \times 25 \mathrm{~mm} \times 150 \mathrm{~mm}$ and (c), (d) $40 \mathrm{~mm} \times 40 \mathrm{~mm} \times 200 \mathrm{~mm}$ 


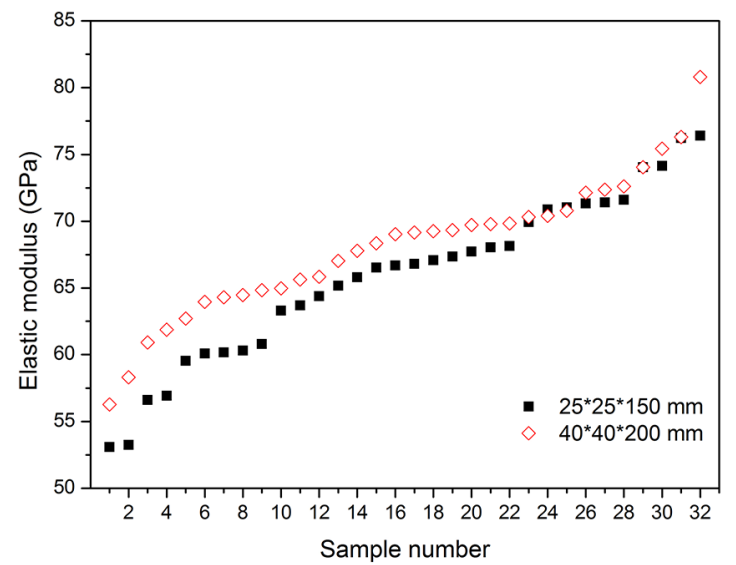

Figure 6. Distribution of elastic modulus of high alumina bricks

a small standard deviation, which was consistent with the lower limit of the sample number given by the literature ${ }^{32}$.

Elastic modulus of high alumina bricks are listed in ascending order as shown in Fig. 6. The elastic modulus of the small and large samples covered the range with 53.1 to $76.4 \mathrm{GPa}$ and 56.3 to $80.8 \mathrm{GPa}$, respectively. The mean values and its standard deviations were $65.9 \pm 6.22$ and $68.1 \pm 5.20$ $\mathrm{GPa}$, which were more than $59.3 \mathrm{GPa}$ of high alumina bricks with $81.7 \% \mathrm{Al}_{2} \mathrm{O}_{3}$ content $^{33}$. Unlike the strength, the larger samples had higher elastic modulus. The results contradict the expected correlation, where the increase of the elastic modulus results in the increase of the mechanical strength for refractories ${ }^{34}$. The exact nature of this phenomenon is not completely clear. There are two possible reasons. One is that the results can be influenced by the fact that the impact intensity is similar for both geometries and the mass in two groups of samples is different. This can result in differences in frequencies produced. Another possible explanation is that the defect in a larger sample has a lower impact on its stiffness and the frequency of vibration than in a smaller sample.

In general, the fracture toughness $\left(\mathrm{K}_{\mathrm{IC}}\right)$ of ceramics was measured by a single edge notched beam test. For the characterization of the nonlinear behavior of refractories, a wedge splitting test was suggested because it could allow the stable crack propagation ${ }^{35}$. However, the requirements of the wedge sample preparation and the operation of the measurement were more rigorous. According to the dependence between $\mathrm{K}_{\mathrm{IC}}$ and the fractal dimension $\mathrm{D}$, the fracture toughness of refractory castables had been estimated based on an equation proposed by Mecholsky et al. as follows ${ }^{36-37}$ :

$$
K_{I C}=E\left(D^{*} a_{0}\right)^{1 / 2}
$$

where E stands for the elastic modulus, the fractal dimension increment is $\mathrm{D}^{*}=\mathrm{D}-2$ for surfaces, the characteristic length $\mathrm{a}_{0}$ is assumed as $0.3 \mathrm{~nm}$.

In this study, the fractal dimension of fracture surfaces was calculated by using the slit island method. Though the difference in the fractal dimension of two sized high alumina bricks was not significant, the larger samples with a higher fracture toughness had a slight lower fractal dimension as listed in Table 3. The similar trend of the concrete was found ${ }^{38}$. Because the bonds among the components and the defects including pores and cracks, the estimated values of high alumina bricks were more close to that of window glass and less than alumina and mullite (Table 3) ${ }^{8,39-40}$.

\section{Conclusions}

In this paper, the investigation of the size effects on the bending strength, elastic modulus and fracture toughness of high alumina bricks was presented. The measurements of two sized samples $(25 \mathrm{~mm} \times 25 \mathrm{~mm} \times 150 \mathrm{~mm}$ and 40 $\mathrm{mm} \times 40 \mathrm{~mm} \times 200 \mathrm{~mm}$ ) were carried out according to $\mathrm{GB} / \mathrm{T}$ 3001-2007. The following conclusions can be drawn from the results: (1) Small samples possessed higher strength. In contrast, large samples had greater elastic modulus. (2) Weibull modulus $m$ of bending strength for high alumina bricks was proportional to the sample size - larger samples demonstrate lower statistical spread. The failure probability and reliability of bricks can be easily calculated by Weibull statistics. (3) From practical point of view, the sample number of high alumina bricks was suggested to be more than 20 for the accurate determination of the average strength with a reasonable standard deviation. (4) The obtained fracture toughness values increased with a decrease in the fractal dimension of the fracture surface determined by the slit island method. There was a positive correlation between the sample size and the fracture toughness. (5) Overall, the evaluation of the strength, elastic modulus and the failure probability based on the data of the larger sample was more appropriate within the range specified by relevant standard.

\section{Acknowledgement}

This work is financially supported by the National Natural Science Foundation of China (NSFC) under Grant No. 51502214. The authors are thankful to Dr. K. Andreev

Table 3. Comparison of fractal dimension and fracture toughness for different materials

\begin{tabular}{lrcccc}
\hline \multirow{2}{*}{ Materials } & \multicolumn{2}{c}{ High alumina bricks } & \multirow{2}{*}{ Window glass $^{8}$} & Alumina $^{39}$ & Mullite $^{40}$ \\
\cline { 2 - 3 } & $25 \times 25 \times 150 \mathrm{~mm}$ & $40 \times 40 \times 200 \mathrm{~mm}$ & & - & - \\
Fractal dimension & $2.376 \pm 0.037$ & $2.366 \pm 0.024$ & - & $3.3-4.3$ & 2.6 \\
$\mathrm{~K}_{1 \mathrm{C}}\left(\mathrm{MPa} \cdot \mathrm{m}^{1 / 2}\right)$ & $0.699 \pm 0.067$ & $0.713 \pm 0.064$ & 0.75 & - \\
\hline
\end{tabular}


of Ceramics Research Centre in Tata Steel for his scientific contribution and for pre-reviewing the paper.

\section{References}

1. Bažant ZP. Size effect on structural strength: a review. Archive of Applied Mechanics. 1999;69(9-10):703-725.

2. Zhu T, Li J. Ultra-strength materials. Progress in Materials Science. 2010;55(7):710-757.

3. Huang XX. Size effects on the strength of metals. Acta Metallurgica Sinica. 2014;50(2):137-140.

4. del Viso JR, Carmona JR, Ruiz G. Shape and size effects on the compressive strength of high-strength concrete. Cement Concrete Research. 2008;38(3):386-395.

5. Hoshide T, Sugiyama H. Numerical Analysis of Sample-Size Effect on Strength of Alumina. Journal of Materials Engineering and Performance. 2013;22(1):1-8.

6. Bažant ZP. Size effect. International Journal of Solids and Structures. 2000;37:69-80.

7. Östlund S, Kärenlampi P. Structural geometry effect on the size-scaling of strength. International Journal of Fracture. 2001;109(2):141-151

8. Schacht CA, ed. Refractories Handbook. New York: Marcel Dekker; 2004

9. Aksel C, Riley FL. Young's modulus measurements of magnesiaspinel composites using load-deflection curves, sonic modulus, strain gauges and Rayleigh waves. Journal of the European Ceramic Society. 2003;23(16):3089-3096.

10. Harmuth H. Stability of crack propagation associated with fracture energy determined by wedge splitting specimen. Theoretical and Applied Fracture Mechanics. 1995;23(1):103-108.

11. Palmer GB, Baker G. A load-cycling technique for R-curve behavior: application to a low cement refractory. International Journal of Fracture. 1993;62(3):233-244.

12. Díaz LA, Torrecillas R, Simonin F, Fantozzi G. Room temperature mechanical properties of high alumina refractory castables with spinel, periclase and dolomite additions. Journal of the European Ceramic Society. 2008;28(15):2853-2858.

13. Wereszczak AA, Smith JD, Moore RE. Probabilistic Life Design of Refractories for Steel Casting. In: Proceedings of 34th Annual Symposium on Refractories; 1998 Mar 19-20; Rolla, MO, USA.

14. Shimpo A, Taira H, Hirai N. Mechanical Properties of Monolithic Refractories with Coarse Aggregates and Reliability of the Three-Point Bending Test Using a Standard Brick Shape Test Piece. Journal of Technical Association of Refractories. 2004;24(2):101-107.

15. Palmer GB, Baker G. Specimen size effect on fracture toughness for a low cement refractory. Theoretical and Applied Fracture Mechanics. 1995;22(1):51-61.

16. Schmitt N, Burr A, Berthaud Y, Poirier J. Micromechanics applied to the thermal shock behavior of refractory ceramics. Mechanics of Materials. 2002;34(11):725-747.
17. Curtis RV, Juszczyk AS. Analysis of strength data using two- and three-parameter Weibull models. Journal of Materials Science. 1998;33(5):1151-1157.

18. Ambrožič M, Gorjan L, Gomilšek M. Bend strength variation of ceramics in serial fabrication. Journal of the European Ceramic Society. 2014;34(7):1873-1879.

19. Zapata JF, Gomez M, Colorado HA. Structure-property relation and Weibull analysis of calcium aluminate cement pastes. Materials Characterization. 2017;134:9-17.

20. Segall A, Shelleman D, Pan M, Landy R, Nelson B. A Probabilistic Study of the Influence of Hanger Alignment on the Reliability of Refractory Furnace Roof Anchors. Journal of Testing and Evaluation. 1998;26(2):138-143.

21. Yuan W, Zhu Q, Deng C, Zhu H. The Effect of the Glass Phase on Modulus of Rupture of High Alumina Refractories. Journal of Ceramic Science and Technology. 2015;6(3):215-220.

22. Katayama Y, Hattori Y. Effects of Specimen Size on Strength of Sintered Silicon Nitride. Journal of the American Ceramic Society. 1982;65(10):C164-C165.

23. Nohut S. Influence of sample size on strength distribution of advanced ceramics. Ceramics International. 2014;40(3):42854295 .

24. Hoshide T, Murano J, Kusaba R. Effect of specimen geometry on strength in engineering ceramics. Engineering Fracture Mechanics. 1998;59(5):655-665.

25. Ritter JE. Predicting lifetimes of materials and material structures. Dental Materials. 1995;11(2):142-146.

26. Yuan WJ, Zhu QY, Li J, Deng CJ, Zhu HX. Investigation on Reliability of High Alumina Refractories. Mechanical Properties and Performance of Engineering Ceramics and Composites VIII: Ceramic Engineering and Science Proceedings. 2013;34(2):155159.

27. Zhu QY, Yuan WJ, Zhu HX, Deng CJ. Modulus of rupture distribution of MgO-C refractories. Refractories / Naihuo Cailiao. 2012;46(5):344-346.

28. Zhu QY, Yuan WJ, Deng CJ, Zhu HX. Statistical Analysis of the Flexural Strength for Magnesia-Chrome Refractories via Weibull Distribution. In: Proceedings of the 6th International Symposium on Refractories; 2012 Oct 18-21; Zhengzhou, China. p. 508-511.

29. Bao YW, Zhou YC, Zhang HB. Investigation on reliability of nanolayer-grained $\mathrm{Ti}_{3} \mathrm{SiC}_{2}$ via Weibull statistics. Journal of Materials Science. 2007;42(12):4470-4475.

30. Nukala PKVV, Simunovic S. Scaling of fracture strength in disordered quasi-brittle materials. The European Physical Journal B. 2004;37(1):91-100.

31. van der Zwaag S. The Concept of Filament Strength and the Weibull Modulus. Journal of Testing and Evaluation. 1989;17(5):292-298.

32. Xu YD, Cheng LF, Zhang LT, Yan DT, You C. Optimization of sample number for Weibull function of brittle materials strength. Ceramics International. 2001;27(2):239-241.

33. Ratle A, Lagacé M, Pandolfelli V, Allaire C, Rigaud M. A simple method for evaluating elastic modulus of refractories at 
high temperatures. Journal of the Canadian Ceramic Society. 1996;65(3):202-204.

34. Martinovic S, Majstrovic J, Vidojkovic V, Volkov-Husovic T. Preparation and properties of low cement castable sintered at different temperatures. Processing and Application of Ceramics. 2009;3(4):191-196.

35. Harmuth H, Rieder K, Krobath M, Tschegg E. Investigation of the nonlinear fracture behaviour of ordinary ceramic refractory materials. Materials Science and Engineering: A. 1996;214(12):53-61.

36. Mecholsky JJ, Mackin TJ, Passoja DE. Self-similar crack propagation in brittle materials. In: Varner J, Frechette VD, eds. Advances in Ceramics, Fractography of Glasses and Ceramics. Volume 22. Westerville: American Ceramic Society; 1988. p. 127-134.
37. Yuan WJ, Deng CJ, Zhu HX. The Influence of $\mathrm{TiO}_{2}$ Addition on the Modulus of Rupture of Alumina-Magnesia Refractory Castables. Journal of Materials Engineering and Performance. 2015;24(8):3100-3106.

38. Saouma VE, Barton CC. Fractals, fractures, and size effects in concrete. Journal of Engineering Mechanics. 1994;120(4):835854 .

39. Casellas D, Ràfols I, Llanes L, Anglada M. Fracture toughness of zirconia-alumina composites. International Journal of Refractory Metals and Hard Materials. 1999;17(1-3):11-20.

40. Vales F, Rezakhanlou R, Olagnon C. Determination of the fracture mechanical parameters of porous ceramics from microstructure parameters measured by quantitative image analysis. Journal of Materials Science. 1999;34:4081-4088. 